\title{
5. COMMISSION DES ANALYSES DE TRAVAUX ET DE BIBLIOGRAPHIE
}

\section{Report of Meeting, 26 August 1964}

Président: J. Kleczek.

SECRÉTAIRE: J. B. Sykes.

The meeting opened at $10^{\mathrm{h}} 45^{\mathrm{m}}$.

The President asked for any corrections or changes needed in the Draft Report to be sent to him in writing for inclusion in the Transactions, Volume XIIB.

The President stated that, in accordance with the recommendation of the Executive Committee, no change was proposed in the officers of the Commission at this General Assembly, and that in view of the small size of the Commission it was not thought necessary to appoint an Organizing Committee.

Dr Pecker presented on behalf of Prof. Lacroute a proposal from the French National Committee for Astronomy calling attention to certain difficulties in the acquisition of astronomical publications under the present system of journals and observatory publications, and suggesting the establishment of a grouping of countries in order to reduce the number of different publications and in order to standardize systems of exchange of publications. After discussion it was agreed that a Committee of the Commission, consisting of Lacroute (Chairman), Kleczek, Martynov and Sykes should be formed to discuss the proposal in detail and should hold its first meeting during the General Assembly. Prof. Goldberg was also invited to participate in order to represent the U.S.A. but was unable to do so.

(This Committee met on 29 August at $8^{\mathrm{h}} 3^{\circ} \mathrm{m}$. Lacroute gave further details of the proposal, using France as an example, whereby one or more of the present subscription journals such as Annales d'Astrophysique might be used as an exchange unit on behalf of all French observatories, and would no longer be available on subscription. Sykes pointed out that such journals were taken by many libraries other than astronomical ones. Kleczek remarked on the difficulties of small countries such as Czechoslovakia and did not think it would be easy for such countries to form groups as suggested in the proposal. He also considered that the established journals would not be willing to change their status so radically. Sykes proposed, and it was generally agreed to recommend, that the larger countries should be generous with their distribution of publications on exchange and should not compel the smaller countries to generate unnecessary literature in order to obtain all the publications which they wish to receive from the larger countries. The same should apply to large institutions having several series of publications.)

Dr Pecker made a personal statement calling attention to the absence from Commission 5 of both astronomical librarians and editors of astronomical journals, whereas collaboration with both these groups would be highly desirable in order to deal with the ever growing accumulation of information in astronomy as in other fields. He reported that there is a proposal to form an association of astronomical librarians within the International Federation of Librarians' Associations, and suggested (I) a resolution expressing the Union's approval of this, (2) the formation of a Committee of Commission 5 with co-opted consulting members (if and when the proposal to allow such members of the Union comes into force) representing librarians and editors, to discuss in particular problems of references, transliteration, abstracting and classification.

On this proposal Belorizky remarked that many small observatories have no professional librarian. Pecker replied that this was one reason for setting up such a Committee, so as to 
deal with any resulting problems. Luplau fanssen asserted that the large and the small observatories have different library problems and need different systems, and that in his opinion the need in a small observatory is for a person with mainly astronomical training. Bourgeois referred to the ICSU Abstracting Board and to the need for full and rapid international collaboration in the exchange of information.

It was agreed that such a resolution should be submitted, and that a Committee consisting of Bourgeois (Chairman), Harwood, Kleczek, Ogorodnikov and Pecker should be formed to consider this problem, and a first meeting during the General Assembly was arranged.

(This Committee met on 28 August at $8^{\mathrm{h}} 00^{\mathrm{m}}$. After discussion it was agreed that Kleczek should act as Chairman of a permanent Committee of the Commission including also Bourgeois, possibly other members of the Commission, two or three librarians of astronomical institutions, and two or three editors of leading astronomical journals. Some possible members of the Committee were mentioned but it was agreed to wait until the election of co-opted consulting members of the Union was authorized, before taking any further steps. The representation of both small and large libraries was agreed to be desirable where possible. Furthermore, this Committee is to discuss the problem of revising the Universal Decimal Classification schedules for astronomy (see below) and to report on the matter before the next General Assembly.)

Prof. Velghe raised the subject of Les observatoires astronomiques et les astronomes. He commented that the book was out-of-date as soon as published owing to the incessant changes of staff and equipment, and asked the Commission's opinion concerning a proposal to replace it by a card index for which replacement cards could be issued whenever the information concerning a particular observatory became obsolete. Sykes suggested that for this particular publication a loose-leaf page system might be more appropriate, and called attention to the flexibility of arrangement of either system to suit each user's convenience. Dermul pointed out the problem of keeping the name indexes up-to-date when using a card or similar system. Luplau Yanssen said that it would be a great help if every published paper carried the address of the author. Pecker asked whether financial support would be needed. Velghe replied that he could not yet say how much the proposed scheme would cost, but he was sure that it would be much cheaper than the present method of publication. Bourgeois expressed the opinion that the prime need was for up-to-date information on instruments and on subject fields of interest to observatories. To a question from Sykes, Velghe agreed that observatories were not always sufficiently co-operative in providing information.

The Commission expressed approval of Prof. Velghe's proposal.

Prof. Ogorodnikov stated that the Universal Decimal Classification was now in use in the Soviet Union as well as in other countries, and that the schedules for the astronomy section had not been revised for many years, and suggested the formation of a Committee to investigate and propose improved schedules. At the suggestion of the President it was agreed that this should be part of the duties of the Committee (see above).

The President reported a proposal from Dr Link to unify and simplify the style of astronomical references, for example by adopting a uniform placing of the year of the work cited. Pecker said that the Presidents of some other Commissions had also privately suggested to him the uniform adoption of the system in which the year follows directly after the author's name, with corresponding references in the text. The Commission agreed that greater uniformity would be desirable. Bray remarked on the disadvantages of the now general abandonment of the practice of giving the titles of papers cited.

Dr Beer reported that there were good prospects that Dr Michael Hoskin, of the History of Science Department at Cambridge, England, would be willing to assist in the Bibliography of Astronomy $188 \mathrm{r}-1898$ as regards British publications of the period. He thought that $\mathrm{Dr}$ Hoskin might be willing to collaborate even if the Union could give no financial support, 
although such support would be most welcome to cover expenses of work by research students etc. Dermul reported that contributions were complete or almost complete from 2 I countries, partly complete from eight (including France, Germany, Great Britain and the U.S.A.) and lacking from 20, of which eight certainly or probably had no publications from that period to report. He had at present some 40000 slips. Harwood reported that the U.S.A. contribution was only one-third submitted and might take another year to complete. A meeting was arranged between Beer, Dermul, Harwood, Kleczek and Sykes to discuss future action.

('This meeting took place on 27 August at $13^{\mathrm{h}} 30^{\mathrm{m}}$. The total number of slips is expected to be of the order of 50000 . It was thought that they should be published in book form and not merely kept as a reference collection, partly for safety and partly because the HouzeauLancaster Bibliography and the Astronomischer fahresbericht are in book form. The question of finding a publisher was discussed. Dermul said that the IAU did not look with favour on the idea of itself publishing and selling the work. Sykes suggested that the Holland Press, which had just published the revised edition of the Houzeau-Lancaster Bibliography, might be willing to undertake some or all of the work as a commercial proposition.

A print size of 500 was thought to be appropriate, this being the number of copies of the Astronomischer fahresbericht at present printed. The above possibilities of publication would be explored by Kleczek, and meanwhile Beer was asked to continue with the idea of collaboration by Dr Hoskin in preparing the British contribution. A sum of $£ 5^{\circ}$ to $£$ roo to support this work would be mentioned to the Finance Committee as suitable if requested. For the time being there would be no deadline for contributions, but as soon as possible a statement would be issued laying down a date after which no further contributions could be accepted. This date might be different for different subject fields if it proved advisable for the volumes of the work pertaining to different subjects to be published at different times.)

Dr Moreton proposed the establishment of a bibliography of transient solar effects permitting the determination of what information existed concerning any given event. The Commission approved the suggestion in principle but felt that Commission ro should be responsible for arranging details of the system.

Dr Belorizky pointed out that the Referativnyi Zhurnal for astronomy appears considerably in advance of the English, French and German abstract journals and contains much more informative abstracts. He raised the question whether it could be made available in translation. The meeting did not appear to consider this an easily practicable idea.

Prof. Martynov showed at the meeting a published copy of the fourth volume of the Bibliography of spectroscopic binaries, mentioned in the Draft Report as being in press. Dr Beer showed a copy of the first volume of the new edition of Houzeau and Lancaster's Bibliographie générale de l'astronomie, recently published by the Holland Press, London. 